\title{
The DSM IV diagnoses of melancholic and atypical depression in pregnancy
}

\author{
Martin Kammerer • Vivette Glover • \\ Claudia Pinard Anderman • Hansjörg Künzli • \\ Alyx Taylor • Brida von Castelberg • Maureen Marks
}

Received: 23 March 2010 /Accepted: 9 September 2010/Published online: 15 October 2010

(C) Springer-Verlag 2010

\begin{abstract}
Atypical and melancholic subtypes of depression based on the Diagnostic and Statistical Manual (DSM) IV are important concepts, especially for biological psychiatry. The aim of this study was to determine whether the symptoms used for the diagnoses of atypical and melancholic depression can distinguish these subtypes during pregnancy. A modified version of the Structured Clinical Interview for DSM IV (SCID interview) was used that allowed assessment of all DSM IV symptoms of melancholic and atypical depression with depressed and non-depressed women in pregnancy. A
\end{abstract}

\footnotetext{
M. Kammerer $(\triangle) \cdot$ V. Glover $\cdot$ A. Taylor

Imperial College London, Institute of Reproductive and Developmental Biology,

Du Cane Road,

London W12 ONN, UK

e-mail: M.Kammerer@imperial.ac.uk

M. Kammerer $\cdot$ M. Marks

Institute of Psychiatry, King's College London,

De Crespigny Park,

London SE5 8AF, UK

A. Taylor

School of Biomedical and Health Sciences,

Franklin-Wilkins Building, King's College London,

Stamford Street,

London SE1 9NH, UK

M. Kammerer • C. Pinard Anderman · H. Künzli

Department of Applied Psychology,

Zurich University of Applied Sciences,

Minervastr. 30,

CH 8032 Zurich, Switzerland

B. von Castelberg

Department of Obstetrics and Gynaecology,

Stadtspital Triemli Zurich,

Birmensdorferstr. 501,

CH 8063 Zurich, Switzerland
}

Swiss cohort of 449 women was interviewed. Four diagnostic groups were compared: women with melancholic, atypical or non specified depression, and those without depression. Seventeen per cent of the cohort met SCID criteria for a depressive episode of depression at least once in pregnancy, with melancholic depression $2.4 \%$, atypical depression $4.4 \%$ and non specified depression $10.2 \%$. Many of the symptoms used to distinguish atypical and melancholic depression did not discriminate between these groups during pregnancy. However some, such as mood reactivity, distinct quality of mood and sleep pattern, did discriminate. Differential diagnosis between melancholic and atypical depression in pregnancy needs to be based on pregnancy specific definitions. The possible therapeutic consequences and the neurobiological basis for these findings warrant further research.

Keywords Diagnosis - Classification · Pregnancy · Melancholic depression - Atypical depression - Depression . Affective disorders

\section{Introduction}

The melancholic and atypical subtypes of depression, characterised as "specifiers" by the Diagnostic and Statistical Manual (DSM IV; APA 1994) are well established. Different responses to medication (e.g. iproniazid shows better response to atypical depression compared to melancholic depression (West and Dally 1959a, b)) initially led to the concept of melancholic and atypical depression. More recent studies have investigated treatment response in atypical as opposed to melancholic depression, e.g. Mannel et al. 2010. The finding that the two groups show the extremes of HPA axis function strengthened the importance of this diagnostic concept. Recently, psychological characteristics, e.g. the 
response to the attachment assessment (with significantly lower secure attachment scores with atypical depression compared to melancholic depression) hint at different psychological aspects of the two diagnostic groups (Levitan et al. 2009). Thus both from the perspective of optimal medication and from that of potential associated psychological symptoms, it may be important to characterise the nature of depression into melancholic and atypical subtypes, during pregnancy as well as at other times.

Dichotomised extremes of associated symptoms of depression are used for the differential diagnosis between melancholic depression and atypical depression: excitability versus loss of interest, overeating versus loss of appetite, oversleeping versus sleeping problems. In addition, symptoms specific for either condition are used: feelings of leaden paralysis and rejection sensitivity are counted as specific symptoms for the diagnoses of depression with atypical features. For depression with melancholic features these are that depressed mood is worse in the morning, feelings of excessive or inappropriate guilt, symptoms of marked motor retardation or agitation, and the distinct quality of the depressed mood. The latter means that the depressed mood is experienced as distinctly different from the kind of feeling experienced after the death of a loved one.

Data from the National Comorbidity Survey $(N=4,907$, Matza et al. 2003) using the Composite International Diagnostic Interview (WHO 1990) and data from a large American twin registry sample $(N=6,846$; Sullivan et al. 2002) have strengthened the evidence for the existence of these subtypes. A recent comprehensive review by Stewart et al. has confirmed the validity of these diagnoses (Stewart et al. 2009). However, the reliability of these two diagnostic concepts has never been studied in pregnancy.

There are substantial physiological changes during pregnancy that might affect the frequency of symptoms like sleep and appetite problems, even among non-depressed women (Kammerer et al. 2009). There are also major changes in the function of the hypothalamic-pituitary-adrenal (HPA) axis (Magiakou et al. 1997; Kammerer et al. 2002, 2006; Taylor et al. 2009) and the hypothalamic-pituitary-gonadal axis (Bloch et al. 2004). There is evidence that atypical depression and melancholic depression are characterised by different alterations in the function of the HPA axis. For example, whereas melancholic depression is associated with increased activity, atypical depression is associated with reduced cortisol output (Gold and Chrousos 2002), and an altered cortisol response to desipramine injection (Asnis et al. 1995; Tops et al. 2008). A blunting of the cortisol awakening response has been found in both rejection sensitivity (Tops et al. 2008) and postpartum depression (Taylor et al. 2009). An increased feedback function of the hypothalamic-pituitary-adrenal (HPA) axis was found with atypical depression in contrast to melancholic depression
(Levitan et al. 2002). However it is unknown whether these differences are also true during pregnancy when cortisol levels rise markedly. In pregnancy, the placenta plays a key role by producing corticotropin releasing hormone with a positive feedback regulation of cortisol.

We previously have reported that appetite is not a reliable symptom of depression in pregnancy and postpartum (Kammerer et al. 2009). A recent prospective study of 850 women found that loss of appetite was rare among all postnatally depressed women (Herring et al. 2008). This strengthens the importance of the question to what extent differential diagnosis between melancholic and atypical depression is reliable during the perinatal period.

In this study, our aim was to determine to what extent the current definition of these diagnostic groups, of melancholic and atypical depression, is useful during pregnancy.

\section{Method}

With approval of the ethics committee of the Canton of Zurich, Switzerland, written informed consent was obtained from all participants. Current conditions with psychotic features, current drug or alcohol dependency, or a general medical condition were exclusion criteria.

The SCID interview is specifically designed to assess diagnoses of DSM IV. In order to ascertain information necessary for the diagnosis of a depressive episode, the SCID interview explores symptoms experienced by the proband in the past. In the current study, only the pregnancy time period was assessed. Other episodes of depression that the participating woman may have had experienced earlier in life were not assessed. At interview (6 weeks post partum), the worst 4 weeks in pregnancy were assessed in detail with regard to the presence of the nine SCID symptoms of depression, the eight symptoms of the melancholic specifier of depression, and the five symptoms of the atypical specifier of depression. Usually, the SCID interview regarding these diagnoses and specifiers is finished if the interviewee does not fulfil the entry criteria. The entry criterion for the atypical specifier of depression is the persistence of a positive reaction to positive stimuli and the entry criteria for the melancholic specifier of depression are lack of a positive reaction and/or lack of pleasure in all, or almost all, activities. However in this study, all symptoms of melancholic and atypical depression were assessed with all participants irrespective of whether participants fulfilled the entry criteria for either specifier of depression. This method has not been used before.

In order to ascertain possible differences in distribution between the diagnostic groups, sociodemographic characteristics were recorded at interview. 
Using tape-recorded interviews and repeated interviews with 50 interviews selected at random, the interviewers' judgement and the training psychiatrist's judgements were correlated 0.68 to 0.82 , kappa coefficient (Cohen 1960). The interviewers' ratings were kept in the database. The interviewers were students of psychology, psychiatric nurses and a midwife who had been extensively trained in a series of workshops. A consecutive sample of 449 participants was asked about all symptoms of depression and all the melancholic and atypical symptoms of depression in pregnancy. The sample was divided into four diagnostic groups: depression without specifiers of atypical or melancholic depression (D), atypical depression (AD), melancholic depression (MD) and nondepressed participants (ND). As the melancholic and atypical specifiers exclude each other the two subjects who qualified for the melancholic as well as the atypical specifier were added to the melancholic group only, following the DSM rules.

Using SPSS 12.0, $4 \times 2$ chi-square and post hoc $2 \times 2$ chisquare or Fisher's exact test, when cell sizes were below 6 , were used to test for the significance of differences in proportions. One-way analysis of variance (ANOVA) was used to compare means of normally distributed parametric variables. Sensitivity and specificity of the individual symptoms of melancholic and atypical depression was calculated (Altman and Bland 1994).

\section{Results}

There were no significant differences between the four diagnostic groups, in age, marital status, cohabitation status, socioeconomic status, parity, previous pregnancy loss, medication, smoking, alcohol abuse and illicit drug taking (Table 1).

Seventeen per cent (77/449) of the cohort met SCID criteria for a depressive episode of depression at least once in pregnancy. The percentage of subjects with an episode of depression in pregnancy who met the criteria for the diagnosis for melancholic depression was $2.4 \%$ (11/449), for atypical depression $4.4 \%$ (20/449) and for non specified depression was $10.2 \%(46 / 449)$.

Table 2 shows the percentage reporting each of the melancholic symptoms in the four groups. The symptom of anorexia did not discriminate melancholic depression from any of the other groups. Four of the melancholic symptoms (loss of pleasure, one of the two entry criteria), mood worse in the morning, psychomotor retardation or agitation, excessive and inappropriate guilt, did not discriminate melancholic from atypical depression. Insomnia (sensitivity, 64\%; specificity, $80 \%$ ), and distinct quality of depressed mood (sensitivity, $100 \%$; specificity, 35\%) did discriminate melancholic from atypical depression, as did lack of reactivity to usually

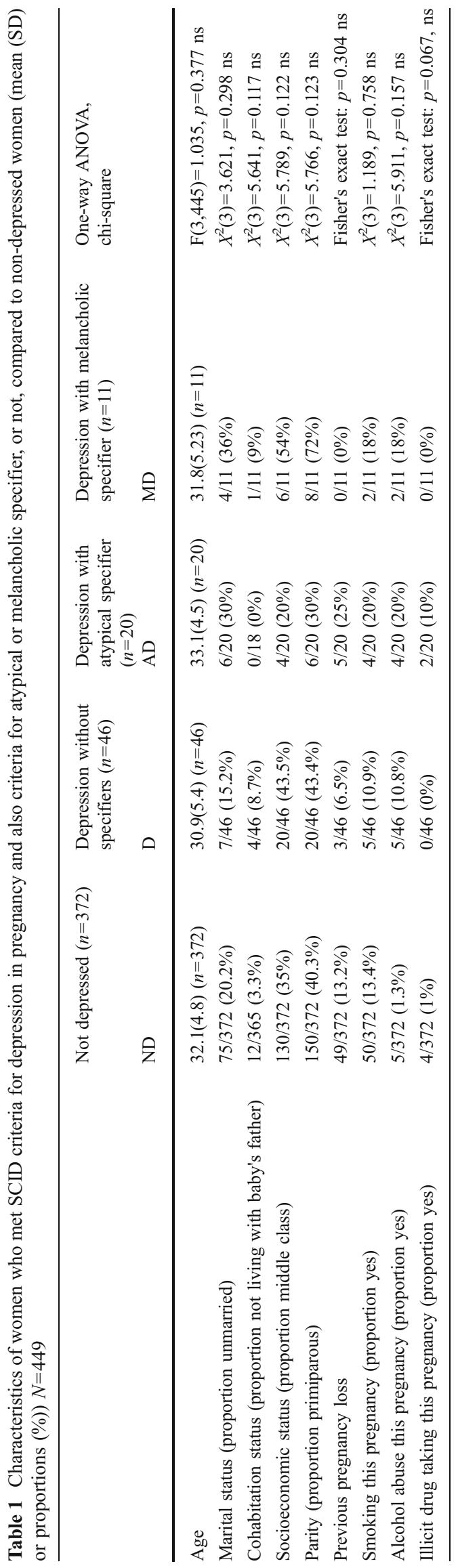


Table 2 Proportion (\%) of subjects meeting criterion on individual melancholic SCID symptoms in pregnancy

\begin{tabular}{|c|c|c|c|c|c|c|c|c|}
\hline \multirow[t]{2}{*}{$\begin{array}{l}\text { SCID melancholic } \\
\text { symptoms }\end{array}$} & \multirow[t]{2}{*}{$\begin{array}{l}\text { Non-depressed } \\
\text { "ND" }\end{array}$} & \multirow[t]{2}{*}{$\begin{array}{l}\text { Depressed without } \\
\text { specifiers " } D \text { " }\end{array}$} & \multirow[t]{2}{*}{$\begin{array}{l}\text { Atypical } \\
\text { depressed "AD" }\end{array}$} & \multirow[t]{2}{*}{$\begin{array}{l}\text { Melancholic } \\
\text { depressed "MD" }\end{array}$} & \multirow{2}{*}{$\begin{array}{l}2 \times 4 \text { chi-squares } \\
\text { or Fisher's exact } \\
\text { test }\end{array}$} & \multicolumn{3}{|c|}{$\begin{array}{l}\text { Post hoc tests }(2 \times 2 \text { chi- } \\
\text { squares or Fisher's exact })\end{array}$} \\
\hline & & & & & & $\mathrm{MD}$ vs. $\mathrm{AD}$ & MD vs. D & MD vs. ND \\
\hline Loss of pleasure & $1 / 372(0.003 \%)$ & $18 / 46(39 \%)$ & $12 / 20(60 \%)$ & 9/11 (81.8\%) & $p<0.001$ & $p=0.262 \mathrm{~ns}$ & $p=0.017$ & $p<0.001$ \\
\hline $\begin{array}{l}\text { Lack of reactivity to } \\
\text { usually pleasurable } \\
\text { stimuli }\end{array}$ & $15 / 372(4 \%)$ & $5 / 46(10.8 \%)$ & $0 / 20(0 \%)$ & $5 / 11(45.4 \%)$ & $p<0.001$ & $p=0.003$ & $p=0.017$ & $p<0.001$ \\
\hline $\begin{array}{r}\text { Distinct quality of } \\
\text { depressed mood }\end{array}$ & $45 / 372(12.1 \%)$ & $23 / 46(50 \%)$ & $13 / 20(65 \%)$ & $11 / 11(100 \%)$ & $p<0.001$ & $p=0.033$ & $p=0.002$ & $p<0.001$ \\
\hline $\begin{array}{l}\text { Mood regularly worse } \\
\text { in the morning }\end{array}$ & $18 / 372(4.8 \%)$ & $4 / 46(8.7 \%)$ & $2 / 20(10 \%)$ & $5 / 11(45.4 \%)$ & $p=0.001$ & $p=0.67 \mathrm{~ns}$ & $p=0.009$ & $p=0.006$ \\
\hline Insomnia & $87 / 372(23.4 \%)$ & $11 / 46(23.9 \%)$ & $4 / 20(20 \%)$ & 7/11 (63.6\%) & $p=0.038$ & $p=0.023$ & $p=0.026$ & $p<0.001$ \\
\hline $\begin{array}{l}\text { Psychomotor retardation } \\
\text { or agitation }\end{array}$ & $37 / 372(9.9 \%)$ & $4 / 46(8.7 \%)$ & $10 / 20(50 \%)$ & $8 / 11(72.7 \%)$ & $p<0.001$ & $p=0.275 \mathrm{~ns}$ & $p<0.001$ & $p<0.001$ \\
\hline $\begin{array}{l}\text { Significant anorexia } \\
\text { or weight loss }\end{array}$ & $11 / 372(3 \%)$ & $3 / 46(6.5 \%)$ & $0 / 20(0 \%)$ & $0 / 11(0 \%)$ & $p=0.445^{\mathrm{e}} \mathrm{ns}$ & na & na & na \\
\hline $\begin{array}{l}\text { Excessive or } \\
\text { inappropriate guilt }\end{array}$ & $9 / 372(2.4 \%)$ & $4 / 46(8.7 \%)$ & $4 / 20(20 \%)$ & $6 / 11(54.5 \%)$ & $p<0.001$ & $p=0.106 \mathrm{~ns}$ & $p=0.002$ & $p<0.001$ \\
\hline
\end{tabular}

${ }^{a}$ i.e. not fulfilling SCID criteria for a DSM IV diagnosis of a depressive episode

${ }^{b}$ i.e. fulfilling SCID criteria for a DSM IV diagnosis of depression

${ }^{c}$ i.e. fulfilling SCID criteria for a DSM IV diagnosis of an atypical specifier of depression

${ }^{d}$ i.e. fulfilling SCID criteria for a DSM IV diagnosis of a melancholic specifier of depression

${ }^{\mathrm{e}}$ A post hoc $2 \times 2$ test for the item anorexia is not applicable as Fisher's exact $2 \times 4$ test provided a non significant result

pleasurable stimuli (which by definition excludes atypical depression; specificity, 100\%; sensitivity, 45\%).

Table 3 shows the percentage reporting each of the atypical symptoms in the four groups. Three out of five atypical symptoms did not discriminate between melancholic depression and atypical depression. Hypersomnia emerges as the only sufficiently sensitive (35\%) and totally specific $(100 \%)$ symptom of atypical depression when comparing atypical depression versus melancholic depression. The criterion of mood reactivity had to be fulfilled by definition in order to be qualified for being considered atypical.

Despite the inability of many of the specifier symptoms to discriminate between melancholic and atypical depression, with the exception of the symptom of anorexia all melancholic and atypical symptoms discriminate their respective specifier from non specified depression. With

Table 3 Proportion (\%) of subjects meeting criterion on individual atypical SCID symptoms in pregnancy

\begin{tabular}{|c|c|c|c|c|c|c|c|c|}
\hline \multirow[t]{2}{*}{ SCID atypical symptoms } & \multirow[t]{2}{*}{$\begin{array}{l}\text { Non-depressed }{ }^{\mathrm{a}} \\
\text { "ND" }\end{array}$} & \multirow[t]{2}{*}{$\begin{array}{l}\text { Depressed } \\
\text { "D" }\end{array}$} & \multirow[t]{2}{*}{$\begin{array}{l}\text { Atypical depressed" } \\
\text { "AD" }\end{array}$} & \multirow[t]{2}{*}{$\begin{array}{l}\text { Melancholic } \\
\text { depressed "MD" }\end{array}$} & \multirow[t]{2}{*}{$\begin{array}{l}\text { Fisher's exact } \\
\text { test }\end{array}$} & \multicolumn{3}{|c|}{$\begin{array}{l}\text { Post hoc tests }(2 \times 2 \text { chi- } \\
\text { squares or Fisher's exact })\end{array}$} \\
\hline & & & & & & $\mathrm{AD}$ vs. $\mathrm{MD}$ & AD vs. $\mathrm{D}$ & AD vs. ND \\
\hline $\begin{array}{l}\text { Mood reactivity: entry } \\
\text { criterion }\end{array}$ & $347 / 372(93.3 \%)$ & $37 / 46(80.4 \%)$ & $20 / 20(100 \%)$ & $5 / 11(45.4 \%)$ & $p<0.001$ & $p=0.001$ & $p=0.048$ & $\begin{array}{l}p=0.628 \\
\text { ns }\end{array}$ \\
\hline $\begin{array}{l}\text { Weight gain or increase } \\
\text { in appetite }\end{array}$ & $146 / 372(39.2 \%)$ & $14 / 46(30.4 \%)$ & $17 / 20(85 \%)$ & $7 / 11(63.6 \%)$ & $p<0.001$ & $\begin{array}{l}p=0.21 \\
\text { ns }\end{array}$ & $p<0.001$ & $p<0.001$ \\
\hline Hypersomnia & $33 / 372(8.9 \%)$ & $6 / 46(13 \%)$ & $7 / 20(35 \%)$ & $0 / 11(0 \%)$ & $p=0.006$ & $p=0.033$ & $p=0.05$ & $p=0.002$ \\
\hline Leaden paralysis & $101 / 372(29.2 \%)$ & $6 / 46(13 \%)$ & $13 / 20(65 \%)$ & $7 / 11(63.6 \%)$ & $p<0.001$ & $\begin{array}{l}p=1.0 \\
\text { ns }\end{array}$ & $p<0.001$ & $p=0.001$ \\
\hline $\begin{array}{l}\text { Interpersonal rejection } \\
\text { sensitivity }\end{array}$ & $74 / 372(19.9 \%)$ & $12 / 46(26.1 \%)$ & $14 / 20(70 \%)$ & $7 / 11(63.6 \%)$ & $p<0.001$ & $\begin{array}{l}p=1.0 \\
\text { ns }\end{array}$ & $p=0.001$ & $p<0.001$ \\
\hline
\end{tabular}

${ }^{a}$ i.e. not fulfilling SCID criteria for a DSM IV diagnosis of a depressive episode

bi.e. fulfilling SCID criteria for a DSM IV diagnosis of depression

${ }^{\mathrm{c}}$ i.e. fulfilling SCID criteria for a DSM IV diagnosis of an atypical specifier of depression

di.e. fulfilling SCID criteria for a DSM IV diagnosis of a melancholic specifier of depression 
the exception of anorexia and mood reactivity all melancholic and atypical symptoms discriminate their respective specifier from the non-depressed group.

\section{Discussion}

Since West and Dally (1959a, b) proposed the term atypical depression in 1959 to describe a type of depression that differed in its symptom profile and response to drug treatment (iproniazid) from other depression, their suggestion has been widely confirmed. Treatment response characteristics with non pregnant patients (Quitkin et al. 1988, 1990; Stewart et al. 1997) and epidemiological data show that the melancholic and atypical specifiers are well established. From a lifetime perspective, a longitudinal overlap of melancholic and atypical depression has been reported (Angst et al. 2007).These authors stress that the longitudinal overlap of melancholia with atypical depression in almost half of all cases may call for comparative analyses of combined, pure and unspecified major depressive episodes.

The identification and validation of these distinct depressive syndromes outside pregnancy can be considered as very well confirmed (Kendler et al. 1996; Kendler 1997). However, in the current study many of the symptoms used outside pregnancy did not distinguish atypical and melancholic episodes in pregnancy. Because of the well recognised issue that the biological signs of pregnancy were sometimes confounded with symptoms of depression a specific screening instrument for depression has been developed for the peripartum, i.e. the Edinburgh Postnatal (sometimes now also called Perinatal) Depression Scale (Cox et al. 1987). We have provided further evidence for this; the DSM IV definition of depression when used in the peripartum needs adaptations (Kammerer et al. 2009). The current study shows that this applies for the melancholic and atypical specifiers when used in pregnancy as well.

This study benefits from the sample under study being consecutive women giving childbirth. However the sample size of the depressed subgroups, and the retrospective nature of the SCID interviews and that the SCID interviews have not been exclusively conducted by mental health professionals (as one of the interviewers was a midwife), are limitations. It is possible that this may have resulted in the high level of $17 \%$ with a SCID diagnosis of depression at least once in pregnancy. However this level is comparable with some other studies. Gavin et al. (Gavin et al. 2005) report combined point prevalence estimates from meta-analyses with a range from $6.5 \%$ to $12.9 \%$ at different trimesters of pregnancy whereas our interviewers assessed the prevalence throughout all three trimesters of pregnancy.

In this study, the proportion of atypical depression (20/77; $26 \%$ ) in our sample of depressed pregnant women is significantly smaller $\left(\chi^{2}=103.8, p<0.0001\right)$ than the percentage reported by Matza et al. (Matza et al. 2003; 304/835; $36.4 \%$ ) from his general sample of depressed participants. His sample was drawn from the National Comorbidity Survey and they were both male and female (the females without definition of their perinatal or non perinatal status). However, the proportion of atypical depression in our whole sample of 449 subjects including depressed with and without specifiers and non-depressed $(20 / 449 ; 4.5 \%)$ is not significantly different in size compared with the data reported by Sullivan et al. from a twin registry cohort (Sullivan et al. 2002; 176/5882; 3\%, $\chi^{2}=$ 2.761, $p=0.1 \mathrm{NS}$ ). Consequently, there is no clear evidence that the overall rates are influenced by pregnancy.

In a representative sample of 800 women in Gothenburg, aged 38-54 years, the point prevalence of major depressive episode according to DSM-III criteria was $6.9 \%$. Of these, $2.9 \%$ had a melancholic episode and $4.0 \%$ a non-melancholic. Unfortunately, the authors did not further disentangle the "non melancholic" group into those suffering from atypical depression and those suffering from unspecified depression. Therefore, comparison with our study is limited. However, their findings (Hallstrom 1984) support the abovementioned conclusion that there is so far no clear evidence that the overall rates of melancholic and atypical depression are influenced by pregnancy.

In summary, the results of this study show that some symptoms used to diagnose atypical and melancholic specifiers of depression did not distinguish these groups from each other during pregnancy. Therefore, adaptation of the definitions of the specifiers of melancholic and atypical depression for use in pregnancy appears to be necessary. It may also be worthwhile considering the use of diagnoses of combined, pure and unspecified major depressive episodes as suggested by Angst et al. in view of their longitudinal data (Angst et al. 2007). The specified atypical and melancholic depression groups and the combined groups of these two might benefit from different kinds of treatment and medication than those who suffer from unspecified depression alone. More research, including into the possible neurobiological causes and underpinnings, is warranted.

Acknowledgements We owe many thanks to the participating women for their help with this study. We thank the heads of the cooperating obstetric departments and their teams for making recruitment possible: Herr Dr. med. D. Behrens, Spital Zimmerberg, Horgen, Herr Dr. med. C. Geschwend, Kreisspital Männedorf, Herr Dr. med. H.-U. Hafner, Gesundheitszentrum Sanitas, Kilchberg, Herr Dr. med. R. Müller, Kantonsspital Winterthur. This research was supported by grant Nr. 103549 PND HAP of the Ministry of Education of the Canton of Zurich, Switzerland, and by an Independent Medical Research Grant given by Pfizer (Schweiz) AG.

Declaration of interest The study was funded by an independent Medical Research grant given by Pfizer Schweiz (AG) and by the Ministry of Education of the Canton of Zurich, Switzerland. 


\section{References}

Altman DG, Bland JM (1994) Statistics notes: diagnostic tests 1: sensitivity and specificity. BMJ 308:1552

Angst J, Gamma A et al (2007) Melancholia and atypical depression in the Zurich study: epidemiology, clinical characteristics, course, comorbidity and personality. Acta Psychiatr Scand Suppl 433:72-84

APA (1994) Diagnostic and statistical mannual of mental disorders (4th ed) (DSM-IV). APA, Washington

Asnis GM, McGinn LK et al (1995) Atypical depression: clinical aspects and noradrenergic function. Am J Psychiatry 152(1):31-36

Bloch M, Rubinow DR et al (2004) Cortiosol response to oCRH in a model of pregnancy and parturition in euthymic women with and without a history of postpartum depression. J Clin Endocrinol Metab 90:695-699

Cohen J (1960) A coefficient of agreement for nominal scales. Educ Psychol Assess 20:37-46

Cox JL, Holden JM et al (1987) Detection of postnatal depression. Development of the 10-item Edinburgh postnatal depression scale. Br J Psychiatry 150:782-786

Gavin NI, Gaynes BN et al (2005) Perinatal depression: a systematic review of prevalence and incidence. Obstet Gynecol 106(5 Pt 1):1071-1083

Gold PW, Chrousos GP (2002) Organization of the stress system and its dysregulation in melancholic and atypical depression: high vs low CRH/NE states. Mol Psychiatry 7(3):254-275

Hallstrom T (1984) Point prevalence of major depressive disorder in a Swedish urban female population. Acta Psychiatr Scand 69 (1):52-59

Herring SJ, Rich-Edwards JW, Oken E, Rifas-Shiman SL, Kleinman KP, Gillman MW (2008) Association of postpartum depression with weight retention 1 year after childbirth. Obesity (Silver Spring) 16(6):1296-1301

Kammerer M, Adams D et al (2002) Pregnant women become insensitive to cold stress. BMC Pregnancy Childbirth 2(1):8

Kammerer M, Taylor A et al (2006) The HPA axis and perinatal depression: a hypothesis. Arch Womens Ment Health 9(4):187-196

Kammerer M, Marks MN et al (2009) Symptoms associated with the DSM IV diagnosis of depression in pregnancy and post partum. Arch Womens Ment Health 12:135-141

Kendler KS (1997) The diagnostic validity of melancholic major depression in a population-based sample of female twins. Arch Gen Psychiatry 54(4):299-304
Kendler KS, Eaves LJ et al (1996) The identification and validation of distinct depressive syndromes in a population-based sample of female twins. Arch Gen Psychiatry 53(5):391-399

Levitan RD, Vaccarino FJ et al (2002) Low-dose dexamethasone challenge in women with atypical major depression: pilot study. J Psychiatry Neurosci 27(1):47-51

Levitan RD, Atkinson L et al (2009) A novel examination of atypical major depressive disorder based on attachment theory. J Clin Psychiatry 70(6):879-887

Magiakou MA, Mastorakos G et al (1997) The hypothalamicpituitary-adrenal axis and the female reproductive system. Ann NY Acad Sci 816:42-56

Mannel M, Kuhn U et al (2010) St. John's wort extract LI160 for the treatment of depression with atypical features - a double-blind, randomized, and placebo-controlled trial. J Psychiatr Res doi:10.1016/j.jpsychires.2010.01.010

Matza LS, Revicki DA et al (2003) Depression with atypical features in the National Comorbidity Survey: classification, description, and consequences. Arch Gen Psychiatry 60(8):817-826

Quitkin FM, Stewart JW et al (1988) Phenelzine versus imipramine in the treatment of probable atypical depression: defining syndrome boundaries of selective MAOI responders. Am J Psychiatry 145 (3):306-311

Quitkin FM, McGrath PJ et al (1990) Atypical depression, panic attacks, and response to imipramine and phenelzine. A replication. Arch Gen Psychiatry 47(10):935-941

Stewart JW, Tricamo E et al (1997) Prophylactic efficacy of phenelzine and imipramine in chronic atypical depression: likelihood of recurrence on discontinuation after 6 months' remission. Am J Psychiatry 154(1):31-36

Stewart JW, McGrath PJ et al (2009) DSM-IV depression with atypical features: is it valid? Neuropsychopharmacology 34(13):2625-2632

Sullivan PF, Prescott CA et al (2002) The subtypes of major depression in a twin registry. J Affect Disord 68(2-3):273-284

Taylor A, Glover V et al (2009) Diurnal pattern of cortisol output in postnatal depression. Psychoneuroendocrinology 34(8):1184-1188

Tops M, Riese H et al (2008) Rejection sensitivity relates to hypocortisolism and depressed mood state in young women. Psychoneuroendocrinology 33(5):551-559

West ED, Dally PJ (1959a) Effects of iproniazid in depressive syndromes. Br Med J 1(5136):1491-1494

West ED, Dally PJ (1959b) Effects of ipronizid in depressive syndromes. Br Med J i:1491-1494

WHO (1990) Composite International Diagnostic Interview (CIDI, version 1.0). Switzerland, World Health Organization, Geneva 